\title{
AC 2010-2422: INTEL: PRESENTING REALISTIC EXERCISES IN A STATICS CLASS
}

Christine Valle, Georgia Institute of Technology

Sue Rosser, Georgia Institute of Technology

Janet Murray, Georgia Institute of Technology

Wendy Newstetter, Georgia Institute of Technology

Laurence Jacobs, Georgia Institute of Technology 


\section{InTEL: Presenting Realistic Exercises in a Statics Class}

\section{Abstract}

Statics, a foundational engineering course, introduces a unique approach to problem solving, which is characterized by model-based reasoning. The major intended course outcome is for students to develop the ability to create and utilize free-body diagrams as a mechanism for describing and constraining a problem. This ability to abstract and define an idealized problem from complex objects in the world or textual descriptions ratchets the engineer's ability to solve the problem. Sadly, however, students routinely leave this course having learned to "plug and chug" or jump to a mathematical equation without first defining the problem in a diagrammatic form that articulates the underlying principles. This can lead to serious problems in future courses as the fundamental approach to engineering problem solving has not been understood or embraced. As a foundational course, difficulties here can impact student academic confidence resulting in a diminished sense of self-efficacy that is particularly problematic when amplified by gender and under-represented minorities (URM) issues. And such faltering so early in the major can cause a student to leave engineering.

While difficulties in the course arise for several reasons, our project seeks to address the problem of context. Our hypothesis is that women and minorities particularly, and students generally, are more likely to do well in statics when the problems are placed in the context of real world usefulness. An approach to teaching that effectively scaffolds students' efforts at model building and connects abstract principles/concepts to real world, every day applications will benefit all students while promoting diversity in engineering. Towards that end, we have been developing InTEL (Interactive Toolkit for Engineering Learning), a computer-based manipulable environment that supports teaching and learning in statics by mapping images from real-world environments to abstract diagrams for 2D and 3D equilibrium problems. With such digital technology, statics professors will be able to offer students important scaffolding for developing model-based reasoning by contextualizing abstract concepts and principles in lifelike models. Interacting with and manipulating these models will help students develop the kind of intuition that characterizes engineering reasoning and problem solving.

\section{Introduction}

A substantial body of research has uncovered factors that deter women from engineering, including the following: a technical experience gap relative to their male peers ${ }^{1}$; lower selfconfidence than their male peers ${ }^{2}$; poor quality of classroom experience that leaves women feeling isolated, unsupported and discouraged ${ }^{3}$; not perceiving the practical applications of engineering $^{2}$; not perceiving the creativity and inventiveness of engineering ${ }^{2}$; not perceiving the social usefulness of engineering, particularly to help people ${ }^{2}$. URMs experience similar deterrents, particularly concerning the request for practical applications and the need to overcome the experience gap ${ }^{4}$. In short, research documents that women and URMs are attracted to engineering when they can see its "specific and tangible contributions to society and in bettering local communities, our nation, and the world" 5 . 
Statics is a foundational course that introduces the engineering approach to problem solving, which is a unique, model-based mode of reasoning. At the heart of the Statics course is an understanding of the free-body diagram and its pivotal function in describing and constraining a problem. The ability to abstract and define a problem from objects in the world or textual descriptions by forming an appropriate idealized model ratchets the engineer's ability to solve the problem. Sadly however, students routinely leave this course having learned to "plug and chug" or jump to a mathematical equation without first defining the problem in a diagrammatic form that articulates the underlying principles. In short, they rely on rote application of equations without understanding that the mathematics are an outcome of a preliminary step of model formation. Difficulty in this fundamental cognitive act of model building can cause a lack of confidence and a diminished sense of self-efficacy that is particularly problematic when amplified by gender and URM issues.

An approach to teaching and learning statics that effectively scaffolds students' efforts at model building and connects abstract problems with multiple real world applications would be of benefit to all students and would be particularly helpful in promoting diversity in engineering. One notable step in this direction is the recent textbook Statics: Analysis and Design of Systems in Equilibrium, in which the authors, Sheri D. Sheppard and Benson H. Tongue, include extensive real world case studies such as the Golden Gate Bridge and build problem sets around a methodology that make explicit use of the free-body diagram, including such sketches in plentiful illustrations ${ }^{6}$. But the page-based examples do not allow for manipulation, so the arrows on the page can remain hard to map to the physical interplay of objects in space. A computer-based interactive system in which images from the real world are mapped to abstract diagrams representing various interactions of objects in space (e.g. frame versus truss problems, friction, etc) can help students make these crucial connections.

\section{Approach - Assumptions to make when dealing with realistic problems}

Our funding was awarded on March 1 2007. We have created a public website where we post completed exercises as well as news of the project. The public website is viewable at http://intel.gatech.edu. Our group and the various tasks each sub-group performs have been described in our past 2 ASEE conference papers ${ }^{7,8}$.

While working to improve statics knowledge is not new ${ }^{9-13}$, our approach is different in that we use realistic exercises that students can relate to in their everyday life, presented in a gaming online environment that will appeal to twenty-some year olds. Many students are completely turned off by classic textbook statics exercises, most of which don't engage their minds in today's world, and aren't practical. However, realistic structures are complex and their design is beyond the knowledge base of a statics student. As a result, sometimes difficult decisions must be made to render the problems statically determinate. However, we believe this will help reinforce the importance of adequate modeling in engineering to students, and serves a valuable purpose as a motivation for, and preparation to, more complex classes like Deformable Bodies or Dynamics.

Some of the exercises we have developed, implemented, tested, and successfully assign to students every semester now include: 


\begin{tabular}{|l|l|l|}
\hline \multicolumn{1}{|c|}{ TOPIC } & \multicolumn{1}{|c|}{ PROBLEM } & \multicolumn{1}{c|}{$\begin{array}{c}\text { MODIFIED FOR } \\
\text { STATICS }\end{array}$} \\
\hline Moment in 2D, Free-body Diagram & Seesaw & $\mathrm{N}$ \\
\hline Equilibrium of 1 rigid body / Frame & Arm-Purse & $\mathrm{Y}$ \\
\hline $\begin{array}{l}\text { Truss: Method of Joint/Method of } \\
\text { Section }\end{array}$ & Minneapolis Bridge & $\mathrm{N}$ \\
\hline Distrib. Load, Centroid & New Orleans Levee & $\mathrm{N}$ \\
\hline Frame & Keyboard & $\mathrm{N}$ \\
\hline Frame/Truss & Bicycle & $\mathrm{Y}$ \\
\hline
\end{tabular}

Table 1. List of online exercises

Figure 1 shows the main presentation screen for the arm and purse problem. This is a frame problem, but we assign it to students as a two-step, one body equilibrium problem at the beginning of the semester. The first body they study is the lower arm, and they must solve for the unknown forces in the biceps and the elbow. The second body they study is the entire arm (lower arm, upper arm, and biceps). On that body, they must solve for the loads at the shoulder E.

Note that many assumptions must be made to render a realistic arm problem solvable using only statics equations:

- the influence of the triceps muscle, and all other muscles in the arm, is neglected,

- the lower arm is assumed to consist of a single bone, rather than two,

- the real system is in $3 \mathrm{D}$, but we solve the problem in $2 \mathrm{D}$,

- muscles are treated as cables,

- a couple must be placed at the shoulder joint for static determinacy - even though that implies the shoulder joint operates as a fixed support, when in fact it is a ball-and-socket, or pin in $2 \mathrm{D}$, support. 


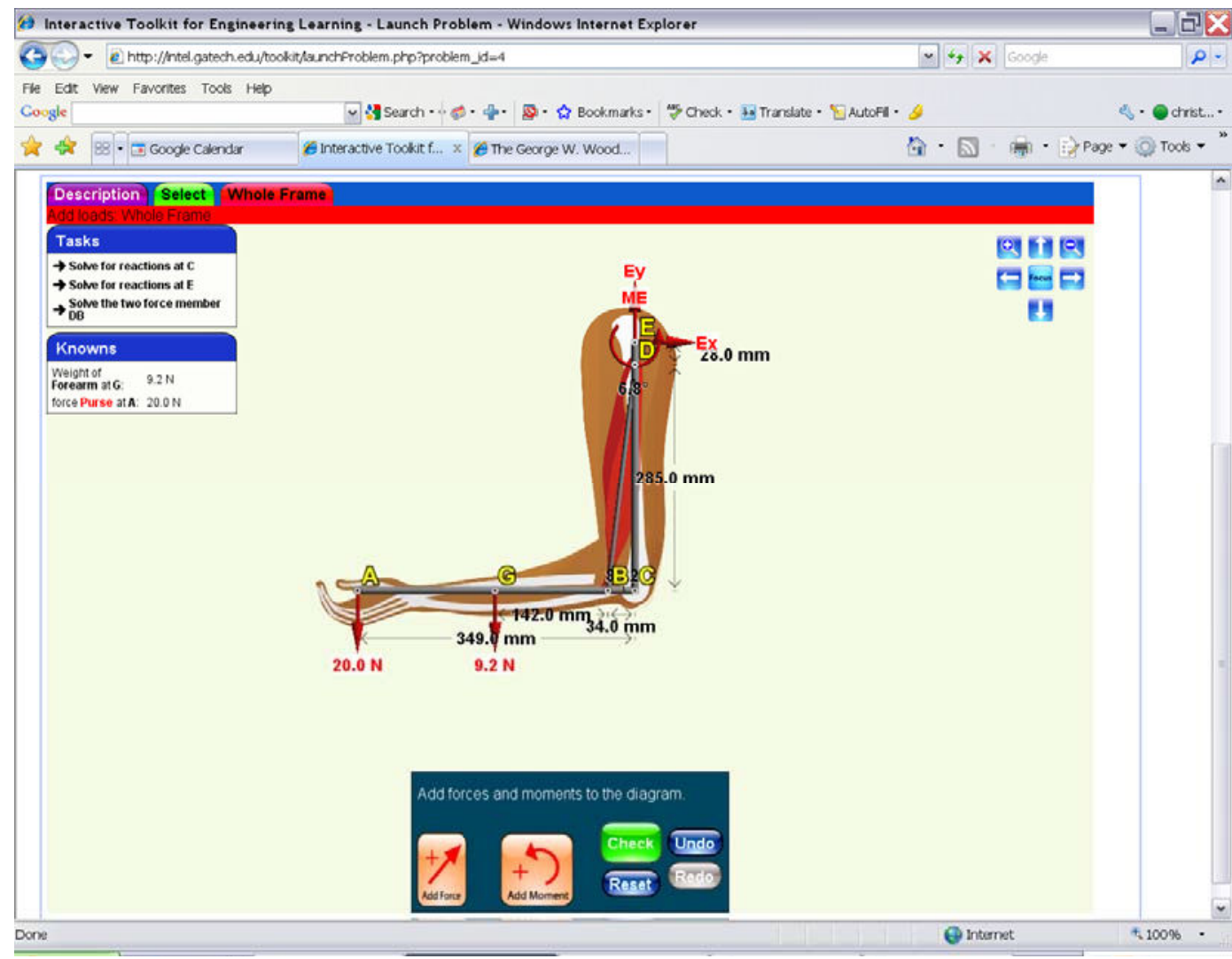

Figure 1 - Arm and Purse Problem

It is important to explain the reasoning behind these assumptions to students before assigning the problem to be solved, or they will not be sensitized to the concept of determinacy and will not understand why we made these assumptions. To that end, each problem comes with a detailed narrative that places the problem in a real-life context students can relate to, explains any assumptions made to the problem, and states what is to be solved in a manner consistent with most textbooks. 


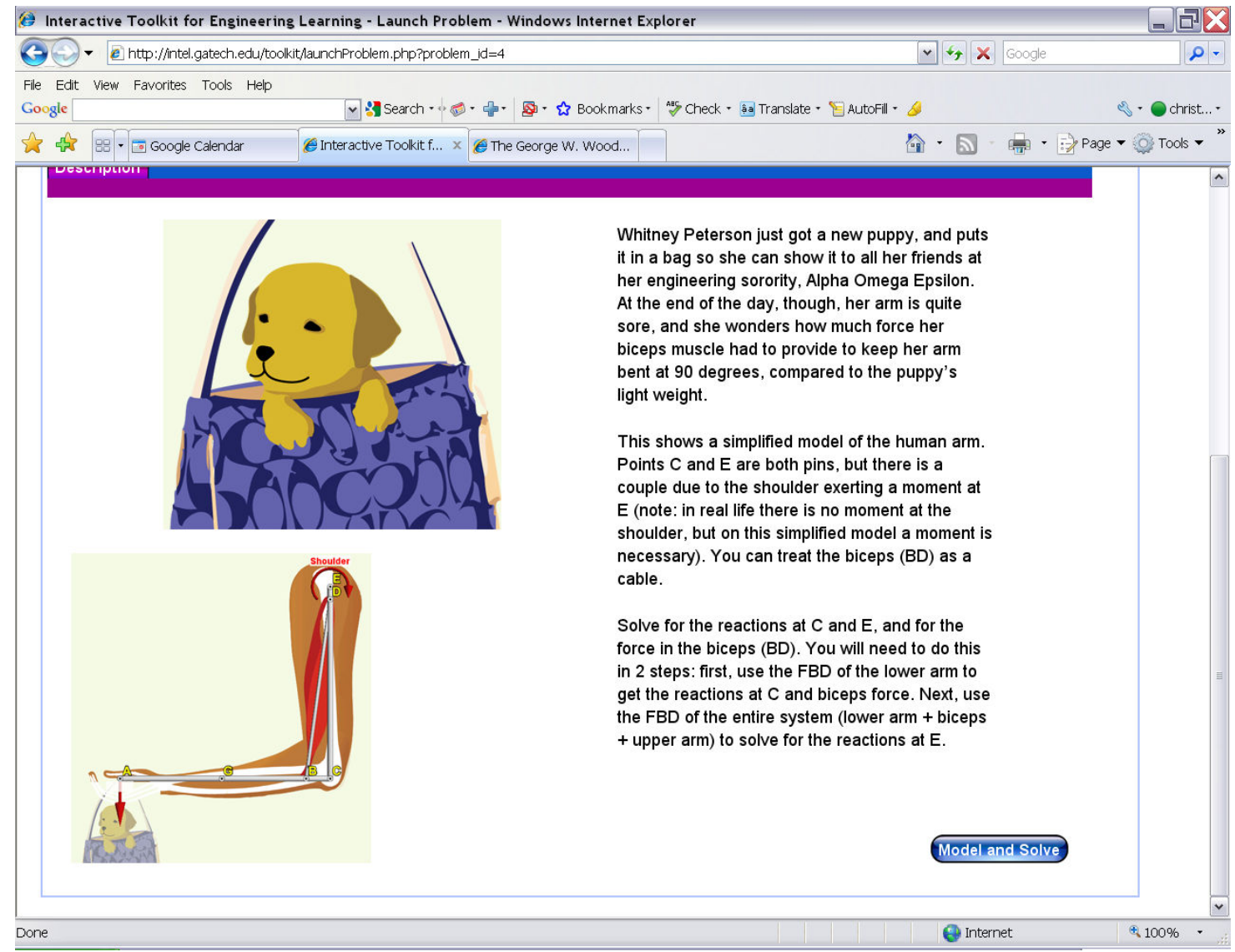

Figure 2 - Narrative for the Arm and Purse Problem

Another problem we developed involves analyzing a typical cross-country bicycle, commonly used by students, and solving the forces on its structure. The goal of this exercise is to calculate all forces in each structural member of the bike. The front member, linking the handle to the front wheel, is a multi-force member, but all other members in the bike are two-force members and form local small triangular trusses. So this is a frame problem, with most members forming a simple truss. The forces in those two-force members are solved using the method of joints.

One key assumption is that the woman riding the bike is going at constant speed (no linear or rotational acceleration, so, this exercise still represents a statics situation). However, friction is acting on the back wheel, and must be neglected in this analysis so as to avoid discussing the dynamics of rolling bodies in a statics class. Therefore, the students are told to assume the center joints in each wheel, where the rest of the frame attaches, are acting as rollers only. 


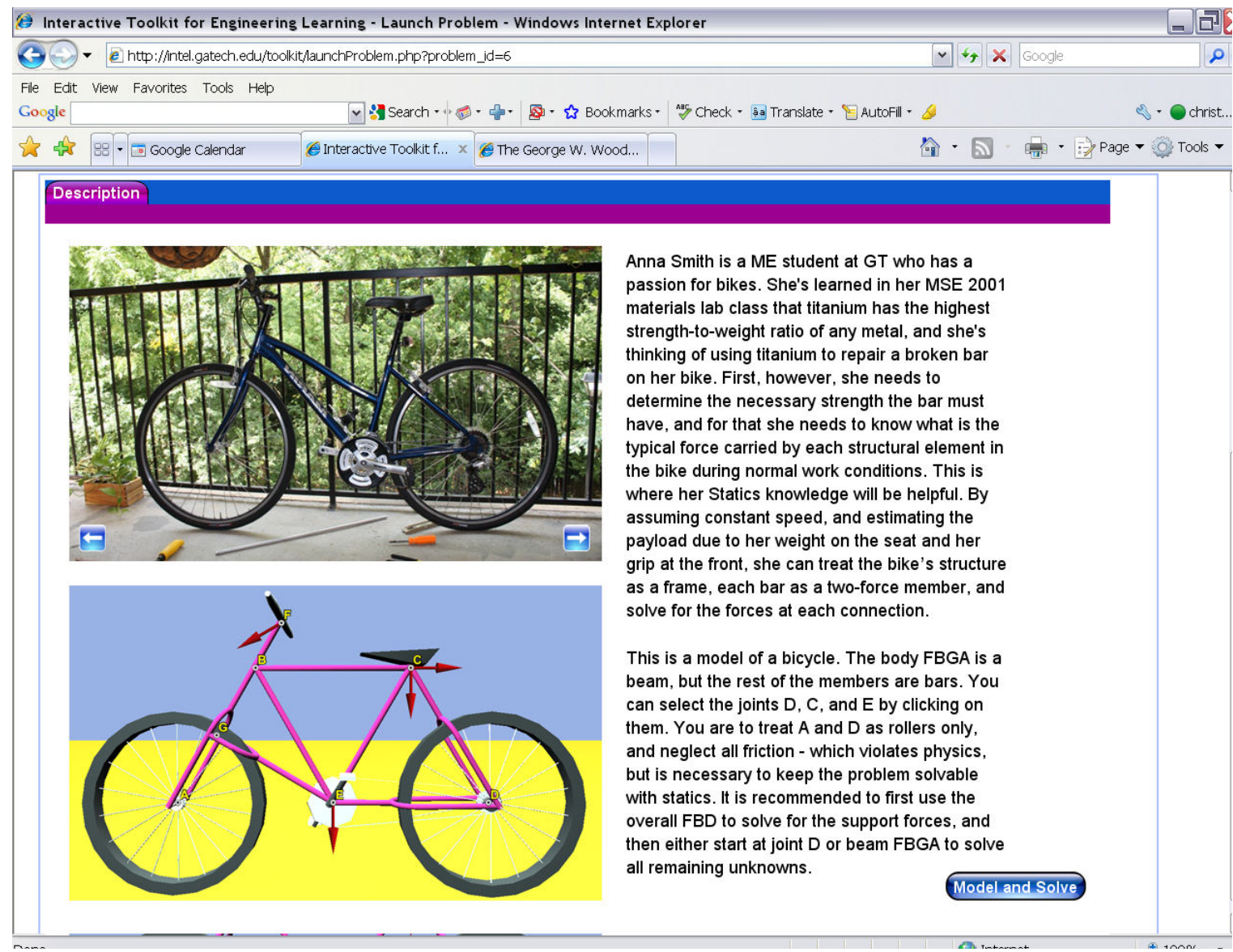

Figure 3 - Narrative for Bicycle Problem 


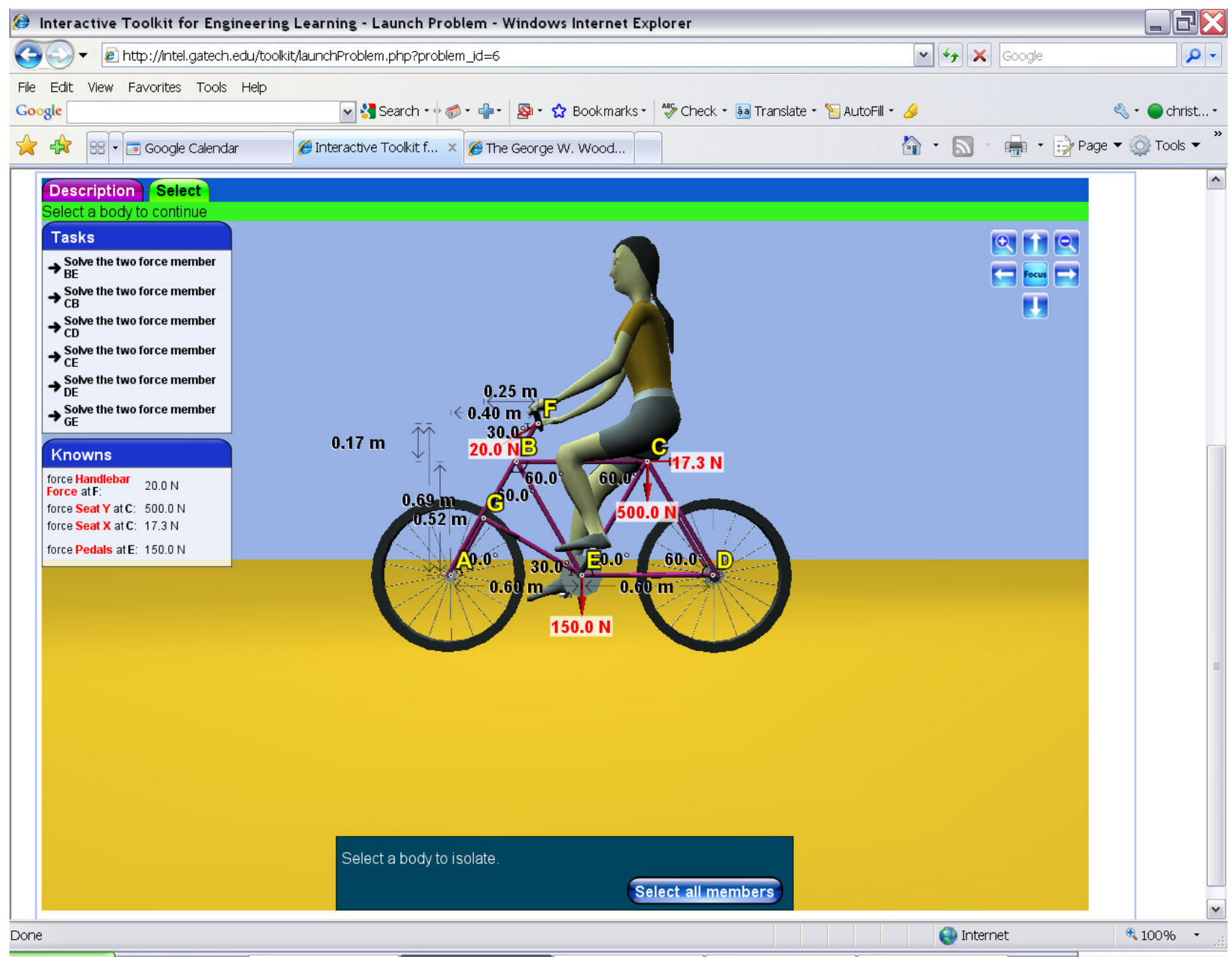

Figure 4 - Woman Riding a Bike (Constant Speed)

\section{Feedback from students}

We currently have about a $70 \%$ rate of success on these problems (that is, about $70 \%$ of the students in each section given the online exercises complete them and find the correct answers). Most of the problems we present do not need to be modified in any major way to render them statically determinate.

Student feedback was solicited in a number of ways: until Fall 2009, informal interviews with a few volunteers (up to 10 students, out of about 120 students per semester who see the interactive modules, also referred to as applet). However, we consistently had trouble recruiting volunteers, even after offering free food or small coupons for ice cream or coffee drinks.

As a result, starting in Fall 2009, we solicited feedback by passing out paper surveys in class after each homework assignment that contains an online problem is graded and returned to 
students (3 surveys total). Since the instructor, Dr. Valle, requires attendance, this seemed a better way to get an accurate global picture of the feelings of the students concerning the online intervention. The response rate ranges from 80 to $90 \%$ and the answers are anonymous. The surveys ask to specify gender and ethnicity (see below in Appendix A).

When the students first encounter the online problems, they struggle with computer glitches, missing Java plug-ins, and learning how to maneuver in the program. As they get more proficient and used to the applet, they report less dissatisfaction with the "mechanics" of the program and enjoy the feedback feature. The control section did not work on the applet at all, but they use the computer to get the instructor's old exams and other class-related documents (which are posted online via a course management software).

\begin{tabular}{|l|r|r|r|}
\hline Population & \multicolumn{4}{|c|}{ \% of population who preferred the applet } \\
\hline & Survey 1 & Survey 2 & Survey 3 \\
\hline Overall & 66.6 & 66 & 59 \\
\hline Men & 63 & 66 & 60 \\
\hline Women & 79 & 69 & 71 \\
\hline Minorities & 64 & 71 & 64 \\
\hline
\end{tabular}

Table 2. Results of opinion surveys after each online exercise

It is clear that our intended target population, women and under-represented minorities, like the applet - even more so than white males. This is a very encouraging result. Our goal, as stated earlier, is to help attract and retain women and URMs to engineering, and as such we do not want to make the applet gender or race neutral. We did not design the applet with the intention of making it equally attractive to all our student profiles.

\section{Conclusion and Future Work}

Based on our work so far, here are our recommendations for further study:

1. We will, of course, keep adding to our library of problems in order to cover all topics of the course. While we started the software with frame problems, which we felt were most crucial to emphasize the concept of the FBD, and have added trusses, centroids, and distributed forces to it, we want to develop 3D problems and friction. This will help us expose our students more and more to the InTEL tools, and hopefully positively impact both their grades in the class and overall satisfaction with engineering.

2. As we include more and more online problems into the course, as homework or extra-credit, the impact on grades and learning may be more easily assessed.

We propose that our software allows for the possibility of a risk-free environment for experimentation and practice. Not all students will enjoy the online environment, but the hope is that by emphasizing "game-like" visuals and the various ways statics is everywhere in everyday life, we will help retain more at-risk students in engineering and show how it can be both fun and rewarding. 


\section{Literature Review}

1. Margolis, J. and A. Fisher, Unlocking the Clubhouse, Cambridge, MA:: MIT Press. 2002.

2. $\quad$ Communications", D.E. Improving Engineering's Public Image-Ten Guiding Principles. Dedicated Engineers Communications Critical Issues Series. 2006 [cited Retrieved 7/6/06.].

3. Selby, C.C., ed. Women in Science and Engineering: Choices for Success. 1999, New York Academy of Sciences: New York.

4. Communications, D.E. Minorities in Engineering \& Related Fields-Diversity Analysis of Students Earning Bachelor's Degrees. Dedicated Engineers Communications Critical Issues Series. 2006 [cited Retrieved 7/6/06.].

5. The Engineer of 2020: Visions of Engineering in the New Century. 2004, Washington, D.C.: The National Academies Press.

6. Sheppard, S.D. and B.H. Tongue, Statics: Analysis and Design of Systems in Equilibrium. 2005, Danvers MA: John Wiley.

7. Ashmore, C., Upton, D., Lee, B. Y., Thomas, G., Harrell, S., Valle, C., Murray, J., Newstetter, W., Jacobs, L. J., Rosser, S., "INTEL: Interactive Toolkit for Engineering Education," ASEE Annual Conference and Exposition, Pittsburgh, June 2008.

8. C. Ashmore, D. Upton, B. Y. Lee, G. Thomas, S. Harrell, C. Valle, J. Murray, W. Newstetter, L.J. Jacobs, and S. Rosser, "INTEL: Promoting Learning and Retention in a Statics Class," ASEE Annual Conference Proceedings, June 2009.

9. Taraban, R., E.E. Anderson, A. DeFinis, A. Brown, A. Weigold, and M. Sharma, "First Steps in Understanding Engineering Students' Growth of Conceptual and Procedural Knowledge in an Interactive Learning Context," Journal of Engineering Education, 96, 57-68, 2007.

10. Taraban, R., A. DeFinis, A. Brown, E.E. Anderson, and M. Sharma, "A Paradigm for Assessing Conceptual and Procedural Knowledge in Engineering Students," Journal of Engineering Education, 96, 335-345, 2007.

11. Litzinger, T., P. Van Meter, M. Wright, and J. Kulikowich, “A Cognitive Study of Modeling During Problem Solving," Proceedings, ASEE Annual Conference and Exposition, Chicago, IL, 2006.

12. P. S. Steif and A. Dollár, "Reinventing the Teaching of Statics," International Journal of Engineering Education, Vol. 21, pp.723-729 (2005)

13. A. Dollár and P. S. Steif, "Learning Modules for Statics," International Journal of Engineering Education, Vol. 22, pp.381-392 (2006)

\section{Appendix A}

This survey is for the test sections:

In the below survey we use the term "homework" to mean the 1-2 problems you have solved for your immediate previous homework assignment. We do not include the Word part of the homework.

1. How many hours would you estimate you put into doing your most recent statics homework assignment? 
2. Doing my recent statics homework assignment helped me understand how statics is put to use in the real world.

$$
\text { TRUE } \quad \text { or } \quad \text { FALSE }
$$

3. In the future I would prefer my homework assignments to be:

$$
\text { COMPUTER-BASED or TEXTBOOK-BASED }
$$

4. One thing I liked about the computer-based problem was:

5. One thing I disliked about the computer-based problem was:

6. Prior to completing this assignment I attempted number of computer-based practice problems. If your answer was 1 or more please state how much time you spent on these practice problems.

Please self-identify your gender by circling one of the following: FEMALE MALE

Please self-identify your ethnicity by placing a check mark in one of the below: African-American Asian-American European-American Hispanic/Latino-American Native American-Indian Other

This survey is for the control section:

In the below survey we use the term "homework" to mean the 1-2 problems you have solved for your immediate previous homework assignment. We do not include the Word part of the homework.

1. How many hours would you estimate you put into doing your most recent statics homework assignment?

2. Doing my recent statics homework assignment helped me understand how statics is put to use in the real world.

$$
\text { TRUE } \quad \text { or } \quad \text { FALSE }
$$

3. In the future I would prefer my homework assignments to be: 


\section{COMPUTER-BASED or TEXTBOOK-BASED}

4. One thing I liked about the textbook-based problem was:

5. One thing I disliked about the textbook-based problem was:

Please self-identify your gender by circling one of the following: FEMALE MALE

Please self-identify your ethnicity by placing a check mark in one of the below: African-American

Asian-American

European-American

Hispanic/Latino-American

Native American-Indian

Other

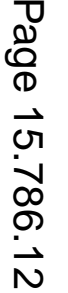

